\title{
CORRECTION
}

\section{Correction to: Non-invasive carbon dioxide monitoring in neonates: methods, benefits, and pitfalls}

Deepika Sankaran (D), Lida Zeinali, Sameeia Iqbal, Praveen Chandrasekharan (D) and Satyan Lakshminrusimha (D)

(c) The Author(s), under exclusive licence to Springer Nature America, Inc. 2021

Journal of Perinatology (2021) 41:2694; https://doi.org/10.1038/s41372-021-01177-5

Correction to: Journal of Perinatology https://doi.org/10.1038/ s41372-021-01134-2

In the original article, under the heading "Types of non-invasive carbon dioxide monitoring" and subheading "Physical method (waveform capnography)", it is mentioned that IR rays are absorbed at a specific wavelength (" $0.43 \mu \mathrm{m}$ ") by $\mathrm{CO}_{2}$ which is an error, and it should read as " $4.26 \mu \mathrm{m}$ ". The original article has been corrected. 